\title{
Maintenance periodontal therapy.
}

Juan Arada (1)

\section{ARTIGO ORIGINAL}

Abstract

Introduction: Maintenance is a fundamental phase of the therapy and prevention of periodontal diseases. The objectives of this review are: a) To determine what are the aspects of maintenance periodontal therapy; b) know the value of maintenance on the long-term results of periodontal treatment; c) review the risk factors of the patient, the tooth and the location; d) establish a protocol of action in the different situations.

Material, methods and results: To carry out this work, 46 scientific articles have been analyzed. The MEDLINE and Cochrane databases were used for the search.

Discussion:The goals of maintenance therapy are to prevent the initiation and recurrence of periodontal diseases. Regardless of the type of treatment we perform, the clinical parameters will not improve if maintenance by the professional is not carried out. To establish the intervals for the appointments and the locations to be treated, it will be essential to assess the risk factors associated with the patient, the tooth and the location.

Key words: Periodontal maintenance, maintenance periodontal therapy, risk of insertion loss, periodontal surgery, causal therapy. 


\section{Terapia periodontal de manutenção.}

\section{Resumo}

Introdução: A manutenção é uma fase fundamental da terapia e prevenção das doenças periodontais. Os objetivos desta revisão são: a) Determinar quais são os aspectos da terapia periodontal de manutenção; b) saber o valor da manutenção nos resultados a longo prazo do tratamento periodontal; c) revisar os fatores de risco do paciente, do dente e da localização; d) estabelecer um protocolo de ação nas diferentes situações.

Material, métodos e resultados: Para a realização deste trabalho, foram analisados 46 artigos científicos. Os bancos de dados MEDLINE e Cochrane foram usados para a pesquisa.

Discussão: Os objetivos da terapia de manutenção são prevenir o início e a recorrência das doenças periodontais. Independentemente do tipo de tratamento que realizemos, os parâmetros clínicos não irão melhorar se a manutenção pelo profissional não for realizada. Para estabelecer os intervalos de consultas e os locais a serem tratados, será fundamental avaliar os fatores de risco associados ao paciente, ao dente e ao local.

Palavras-chave: manutenção periodontal, terapia periodontal de manutenção, risco de perda de inserção, cirurgia periodontal, terapia causal.

Instituição afiliada: 1- Professor Emeritus of the Faculty of Dentistry of Paraguay

Dados da publicação: Artigo recebido em 10 de maio, revisado em 15 de maio, aceito para

publicação em 20 de maio e publicado em 28 de maio.

DOI: https://doi.org/10.36557/2674-8169.2021v3n5p31-48

Juan Arada aradajuan@gmail.com

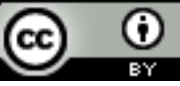

This work is licensed under a Creative Commons Attribution 4.0 International

License. 


\section{INTRODUÇÃO}

The general treatment of patients with caries and periodontal disease, including the associated pathological conditions (pulp and periapical lesions, tooth migration and loss, etc.), can be divided into three clearly differentiable phases, which in many cases overlap:

1. Initial or etiological phase, aimed at eliminating the infection and stopping the progression of the destruction of the periodontal tissues.

2. Corrective phase, aimed at restoring function and aesthetics.

3. Maintenance phase, aimed at preventing the recurrence of cavities and periodontal disease and establishing a series of personal preventive measures in the patient in order to avoid said reinfection.

Periodontal surgery requires a special mention, since in the books they tend to place it within the corrective phase, but as we have seen throughout the development of the monograph, one of the main objectives of the periodontal surgeries that we perform is to eliminate the infection that we had not managed to eradicate in the initial phase of non-surgical treatment. That is why periodontal surgery would be framed between the initial and corrective phase of periodontal disease.

Long-term clinical studies evaluating the effects of periodontal disease treatment have clearly shown that post-therapeutic care by the professional is an integral part of treatment (1-4). This aspect is also the only way to ensure the benefits of long-term treatment. However, it is necessary to carefully evaluate the different maintenance protocols that have been developed in different studies, as well as their external validity, having to assess whether the maintenance that the patients have received is insufficient or if there has been overtreatment.

In recent years, research has focused on looking for patient factors that are associated with a greater risk of disease recurrence; however, the individual risk assessment of each patient is based on a probabilistic estimate centered on the patient. risk to the patient, the tooth and the location (5).

The fact of considering maintenance therapy as a crucial phase in the management of periodontal patients lies in the acceptance that these diseases are caused by the accumulation of bacterial plaque on the surfaces of the teeth. In this regard, 45 years ago it was shown that the accumulation of plaque led to the development of gingivitis and that its elimination returned the state of health to the gingiva (6). Later, it was demonstrated in experimental models that the continued presence of plaque led to 
the development of periodontitis, characterized by the loss of connective tissue and reabsorption of alveolar bone (7). However, there was a group of animals that did not develop the disease despite having been exposed to the same amounts of plaque,which suggests that other aspects such as individual immune response or genetic susceptibility also influence. That is why it seems reasonable to enact that the elimination of bacterial plaque (both by the patient and by the professional) leads to a decrease in gingival inflammation, which entails the maintenance of the health of the gingival tissues and the prevention of the initiation and recurrence of periodontal disease.

From a clinical point of view, these assumptions should be extrapolated to the needs of good personal plaque control, at least in patients susceptible to or treated for periodontal disease. Despite this, not all patients will be able to achieve these objectives, so maintenance by the professional can be crucial to counteract the deficiencies in personal hygiene control. This fact has been studied in an investigation in dogs, in which it was found that in the animals in which an exquisite hygiene control was maintained, the insertion gains observed after scraping were maintained, regardless of whether they had been done or no additional periodic scraping. Conversely, In animals in which hygiene control was not maintained, insertion loss progression was observed, being significantly reduced in those controls that received periodic scraping (8). This suggests that maintenance by the professional could compensate in some way for the deficiencies in personal oral hygiene.

The objectives of this review are:

a) Determine the objectives of maintenance periodontal therapy.

b) Know the value of maintenance on the long-term results of periodontal treatment.

c) Review the risk factors for the patient, the tooth and the location, which may affect the type and temporary location of maintenance therapy.

d) Know the different aspects that we have to assess during the maintenance of periodontal patients and establish a protocol of action in the different situations.

\section{MATERIAS E MÉTODOS}

To carry out this review we have analyzed 46 articles published in scientific journals of dentistry.

For the search we used the MEDLINE databases at www.pubmed.com and Cochrane. Those articles that provide information on maintenance therapy after periodontal surgical treatment have been chosen as selection criteria.

The keywords that have been used are: periodontal maintenance, maintenance 
periodontal therapy, risk of insertion loss, periodontal surgery, causal therapy.

\section{DISCUSSÃO}

\section{Maintenance objectives}

The goal of maintenance should be the preservation of gingival and periodontal health, obtained as a result of the active periodontal treatment phase. Regardless of whether we have decided to restore lost teeth with tooth-borne or implant-borne prostheses, it is essential that the patient is able to maintain good control of the supragingival plaque, for which it is necessary to carry out periodic re-evaluations in which we establish a correct protocol of interception in the event of a possible recurrence, together with continuous psychological and motivational support for our patients.

It is difficult to establish general rules of what the frequency of maintenance should be, but as we will see when analyzing the different risk situations, we will have to assess aspects of the patient, the tooth and the location. The main aspects to be considered are the oral hygiene maintained by the patient, the prevalence of sites with bleeding on probing, and the levels of clinical insertion and the alveolar bone before performing the treatment. In most longitudinal studies, positive long-term results of periodontal therapy were obtained when patients were regularly maintained at 3-6 month intervals, Therefore, it seems reasonable that at the end of the treatment we start with maintenance intervals every 3-4 months and adjust them according to the individual risk presented by each patient (1-4). During the first 6 months after active therapy, there is a remodeling of the periodontal tissues, which are subject to changes. During this phase of tissue healing, it is recommended that a correct professional cleaning protocol be established (9). After this initial phase, it has been seen that the ability of the patient to keep the different surfaces free of plaque is the most important factor to maintain the results of active therapy in the long term, so one of our main objectives is to be motivation and continuous reinforcement of the patient's oral hygiene,both mechanically and chemically, if necessary.

\section{Maintaining the results of active therapy}

Before evaluating the effects of maintenance on the results of periodontal therapy, it is necessary to know the progression of the disease in untreated and poorly maintained patients (at risk of periodontal disease). This aspect has been studied in few investigations and insertion losses of $0.3 \mathrm{~mm}$ each year and annual dental losses of 0.3 to 0.6 teeth per patient have been reported $(10,12)$. If we compare these results with other studies that have evaluated the results of long-term tooth loss ( $>20$ years) in treated and well-maintained patients, we observe that the differences are abysmal, with annual loss results from 0.03 to 0,06 teeth $(13,14)$. 
On the other hand, investigations have been carried out in which patients who have been treated surgically for presenting periodontal disease, but who, for various reasons, have decided not to go for maintenance, have been longitudinally studied. An example is found in a study in which patients, after having been treated surgically, significantly improved all their periodontal parameters, but at 5 years, they showed progression of attachment loss with a rate of $1 \mathrm{~mm}$ per year, regardless of the type of surgery performed. This is a much higher value than the rate we observed of $0.3 \mathrm{~mm}$ (10) in the study in which untreated and unmaintained patients were followed (15). In a similar study in which patients were referred to their general dentist after surgical periodontal therapy, it was observed that $45 \%$ of patients presented complete disease recurrence at 5 years (16).

In another study similar to the previous ones, patients who had been treated for periodontal disease and who refused maintenance were evaluated over a period of more than 5 years. They were able to observe that in these patients there was a significant bone loss, an increase in probing depth (also in the percentages of distribution of the pockets in the different categories) and a dental loss of $6 \%$, being the tooth that was lost the most the second maxillary molar and the one with less the mandibular canine. On the other hand, they observed that teeth with affected furcations worsened more frequently (17).

One of the most important articles in which this aspect has been evaluated is that of Axelsson and Lindhe. They evaluated a group of 72 patients who were treated surgically over a period of 6 years. Two thirds of the patients strictly complied with periodontal maintenance every 2 months for the first 2 years and every 3 months for the subsequent 4 , while the other third was referred to the general dentist. They observed that after the surgical phase there were no differences between the 2 groups for any of the clinical variables analyzed. However, at 6 years of age, the non-maintenance group practically returned to the initial values (before the surgeries), even observing additional insertion losses of $2-5 \mathrm{~mm}$ in $55 \%$ of the locations.In the strict maintenance group, it was observed that the positive results obtained after the surgeries were maintained over time and even improved as the years passed (1).

These articles show us that in patients susceptible to periodontal disease, the fact of not receiving treatment, followed by correct maintenance, jeopardizes the results obtained after the causal phase, even significantly worsening over the years.

Regarding the studies that have evaluated the results of periodontal treatment in patients compliant with maintenance, the main conclusions can be seen below.

In the study carried out by Lindhe and Nyman in 1975, 75 periodontal patients were evaluated who were followed up for 5 years after receiving different modalities of bursa removal surgery. These patients received periodontal maintenance every 3-6 
months, including prophylaxis and instructions on oral hygiene, and it was observed that the improvements obtained after surgical therapy were maintained over the years, even improving some of the parameters (2).

In another study by the same authors, a group of 75 patients with advanced periodontal disease treated with scaling and root planing and periodontal surgeries (modified Widman flap) was followed for 14 years. All the patients were subjected to strict control and maintenance, observing that the successful results of the therapy were maintained in $75 \%$ of the patients, while the other $25 \%$ unpredictably showed additional episodes of insertion loss (4). This shows us that most patients can be treated successfully if they comply with maintenance, although a lower percentage of patients have a high risk of progressive loss of insertion, and it will be our task to identify this group.

Another way to evaluate the maintenance of long-term results has been the evaluation of radiographic bone loss after long periods of time. Thus, 52 patients were followed for 8 years after receiving causal therapy. Those patients who continued with mainte nance visits showed negligible bone loss of $2 \%$ of root length, while those who attended less frequently than one annual visit showed greater bone loss (18).

An important study, due to the long follow-up of their patients, is by Axelsson and Lindhe from 2004. It compares the results of periodontal treatment in 374 patients who were maintained every 2 months for the first 2 years and every 3-12 months between the year. 3 and 30. They were able to observe that the incidence of caries and periodontal disease was very low in this group of patients. In addition, the dental losses observed did not reach $1 \%$ at 30 years and the loss rate was 0.03 teeth per year, the most frequent cause being root fractures. When analyzing the clinical levels of insertion, they observed that in this long period of time only $2-4 \%$ of the sites lost insertion $\geq 2 \mathrm{~mm}$ and that the lingual and interproximal surfaces showed insertion gains of 0.1-0.5 mm (19).

The extreme of how far the benefits of maintenance can go can be found in the 1976 article by Rosling. In this study, 50 periodontal patients were treated with different surgical modalities, after which they received maintenance by the professional every 2 weeks for 2 years. Not only did they observe that all periodontal parameters were reduced and maintained over time, but they also saw that with this strict plaque control regimen they achieved regeneration in interproximal intraosseous defects of up to 3.1 $\mathrm{mm}$, indicating that the healing potential of periodontal tissues is very high as long as there is a complete absence of plaque (3).The problem with this study is its low external validity due to the impossibility of performing maintenance every 15 days on our patients.

Not only has the effect of maintenance on surgical therapy been evaluated. In this context, Nyman and Lindhe in 1979 carried out a study in which they evaluated 225 patients with advanced periodontal disease ( $>50 \%$ of the support lost in the entire 
dentition) during a period of 8 years and who received maintenance by the professional every 3-6 months. The patients were divided into different groups according to the treatment they had received. Thus, there was a group that only received periodontal treatment and another 4 who also received different fixed prosthesis designs. When analyzing the results, they were able to observe that the results improved and were maintained regardless of the group in which the patient was found, that is, that the beneficial results of periodontal treatment can be maintained in the long term if plaque control is good, even when we make fixed prostheses with a multitude of different designs (22).

Another type of therapeutic approach in which the importance of maintenance over long-term results has been seen is furcation treatments. In this regard, the study by Hamp in 1975 stands out, in which 310 multiradicular teeth with different degrees of furcal involvement were evaluated in 100 patients. The treatments they underwent included: RAR, root resections, tunneling, furcation plasties and tooth extraction. After the initial phase, in which $43 \%$ of the teeth were extracted, the patients underwent maintenance appointments that included RAR, instructions on oral hygiene and polishing, every 3-6 months. At 5 years, all teeth remained in the mouth and showed a significant improvement in all periodontal parameters (21).In another attempt to evaluate therapy for furcally involved teeth, but in a much more conservative way, Ross conducted an investigation in 100 patients with 387 maxillary molars with furcal involvement. These teeth were subjected to RAR and furcation plasties, without performing bone surgery at any time. After the initial therapy, the patients entered a quarterly maintenance program for a period of 5 to 24 years, finding that the total survival of the molars studied amounted to $88 \%$ and that a third of the missing teeth remained in the mouth from 11 to 18 years. years (22).After the initial therapy, the patients entered a quarterly maintenance program for a period of 5 to 24 years, finding that the total survival of the molars studied amounted to $88 \%$ and that a third of the missing teeth remained in the mouth from 11 to 18 years. years (22).After the initial therapy, the patients entered a quarterly maintenance program for a period of 5 to 24 years, finding that the total survival of the molars studied amounted to $88 \%$ and that a third of the missing teeth remained in the mouth from 11 to 18 years. years (22).

In another study carried out by Carnevale in 1998, a more resective treatment was performed than in Ross's study, but more conservative than in Hamp's. In 72 patients, root resections or separations were performed and splinted with fixed prostheses. After a 10 -year evaluation period, which included a strict plaque control regimen, a $7 \%$ loss of treated molars was observed, of which a quarter of the losses were due to periodontal reasons. In this way, it is shown that treatment of teeth with furcal involvement, whether resective or conservative, can lead to the preservation of teeth for long periods of time if plaque control is good (23).

Another area in which much importance has been given to the postoperative and 
subsequent maintenance regimen is periodontal regeneration therapy. Many clinical studies show how it is necessary to establish a series of measures after regenerative procedures, especially when we are handling membrane techniques. In this context, we can observe how after regenerative surgery, the results we obtain are better if we apply the following postoperative regimen when we perform guided tissue regeneration techniques: systemic antibiotics for approximately one week, Chlorhexidine 2-3 weeks and prophylaxis by the professional every week during the first more until we carry out the second phase to remove the membranes (in the case of non-resorbable membranes).After removing the membrane, we will repeat the same protocol as when we placed it, with the exception of the antibiotic and, later, we will include the patient in a monthly visit regimen during the first year, after which we will be able to probe again (24).

Summary: Periodontal therapy is effective in improving the clinical parameters of the disease, even in the most advanced cases. Regardless of the surgical technique that we use, it is essential to raise awareness and motivate patients to attend maintenance visits and to maintain correct oral hygiene control, since if not, all the benefits that we have achieved after therapy will be they will lose, and even get worse over time. In addition, we must be clear that this preventive measure not only has to affect periodontal patients or those who are susceptible to the disease, but it will also be essential when it comes to preventing the appearance of gingivitis or periodontitis.

\section{Risk analysis}

The diagnosis during the periodontal maintenance phase should be based on the changes that occur with respect to the results obtained during the treatment phase, which implies that we have to establish a new baseline evaluation after completing the treatment and having restored periodontal health (25).

Our objective during this phase will be to monitor the clinical attachment levels as well as the inflammatory status of the periodontal tissues. That is why the main point of attention is the search for indicators that allow us to determine early that there will be a recurrence of the disease.

The recurrence of the disease will be subject to an imbalance between bacterial aggression and the host's response. That is why risk assessment must be carried out at all levels. In the case of periodontal patients who have been treated, the risk of recurrence will be moderate to high, which is why it will be essential to monitor the risk and provide adequate care for the maintenance of periodontal health. Due to this, it will be necessary to determine the individual risk of each patient in order to establish a maintenance schedule with visits adapted to each one. The next step will be to evaluate the aspects that we have to consider when assessing the individual risk of each patient, each tooth and each location (5): 
a) Patient risk

The risk of each patient must be evaluated taking into account a series of clinical parameters that we must jointly analyze, without giving more importance to one or the other. It will give us information about the state of the health of the periodontal tissues and the risk of the disease progressing. With this objective, Lang and Tonetti (5) constructed a functional diagram that considered the following aspects and that we can see in Figure 1 :

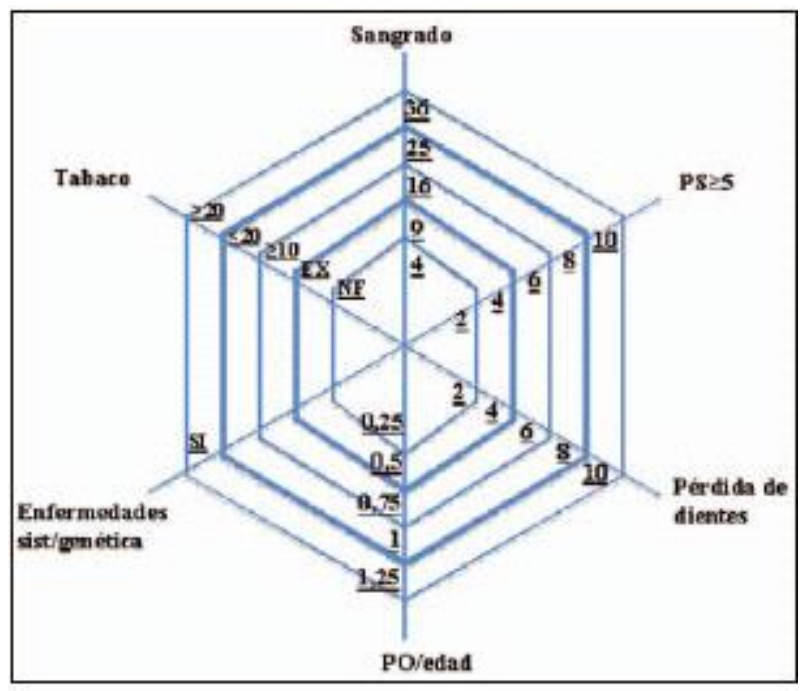

Fig. 1: Diagrama funcional del análisis del riesgo del paciente.

- Percentage of locations with bleeding on probing: bleeding on probing reflects the state of inflammation of the periodontal tissues and the degree of oral hygiene of the patient, although it is not clear what is the value from which the risk increases. In this diagram it has been established that between $0-9 \%$ the risk is low, between $10-25 \%$ the risk is medium and $>25 \%$ is high (26-28).

- Prevalence of residual pockets $4 \mathrm{~mm}$ : It has been shown in different studies that residual deep pockets are associated with a greater risk of developing additional attachment loss, since they are niches that are more easily recolonized by bacteria (27, 29 ). However, it has also been proven that with good periodontal maintenance, disease recurrence can be controlled even when deep residual pockets remain $(4,30)$. In this diagram, individuals with up to 4 residual pockets $>4 \mathrm{~mm}$ are considered to be low risk, 4 to 8 pockets as moderate risk, and $>8$ residual pockets as high risk.

- Loss of teeth out of a total of 28: Although we do not know the reasons for tooth loss, the number of teeth reflects the functionality of the dentition. It is not clear that reduced arches are less functional or lead to mandibular dysfunction (31), however, the number of teeth seems to reflect the history of oral diseases or trauma to which the teeth have been subjected, so it seems It makes sense to include this parameter in the risk analysis. In this diagram, patients who have lost up to 4 teeth out of 28 are considered to be at low risk, 4 to 8 teeth at moderate risk, and $>8$ teeth at high risk.

- Loss of attachment depending on age:Attachment loss based on the patient's age seems to be a good predictor of the risk of future attachment loss, although if we accept the hypothesis that periodontal disease occurs by flare-ups, we cannot rule out future disease recurrence (32). On the other hand, if we accept the hypothesis that in patients with reduced periodontium we will try to maintain the functionality of the teeth for long periods of time, monitoring attachment levels based on age is essential. In this diagram, the following formula is used to determine the risk: measurements have to be made in bitewing radiographs (every $1 \mathrm{~mm}$ represents $10 \%$ of bone loss) or in periapicals (the\% of bone loss is calculated based on of root 
length) to determine the percentage of bone loss.This\% is divided by the age of the patient and the result is a quotient. Based on this quotient, the risk is established, so that values $f 0.5$ imply a low risk, between 0.5-1 a moderate risk and $>1$ a high risk.

- Systemic conditions:As it has been evaluated in reflecting it different studies and in different reviews (Ignacio and Bascones) (33), diabetes mellitus is associated with a greater risk and severity of periodontal disease, in addition to a worse response to treatment, especially in those patients who have poor glycemic control. It is therefore reasonable to think that diabetic patients are at high risk of disease recurrence. Another aspect that is taken into account in this section is that of genetic polymorphisms, the research of which has been gaining momentum in recent years. In this regard, many polymorphisms have been studied, but the only one with which a certain association has been found is the composite IL-1 genotype, especially in Caucasian patients, nonsmokers and $>40$ years (34).In the case of this diagram, the presence of one of these conditions determines that the subject is at high risk, while the absence implies a low risk.

- Tobacco:Tobacco is one of the true risk factors associated with periodontal disease (35). Tobacco has been associated with poorer oral hygiene and alterations in the immune system and, with this, a lower defense capacity against pathogenic periodontiums (36). Furthermore, it has been seen in population studies that smoking patients have a greater severity of periodontal disease (37) and that they respond worse to periodontal treatment, in a dose-dependent manner (38). That is why it seems reasonable to think that smoking patients have a higher risk of disease recurrence. In this diagram, non-smokers and ex-smokers of more than 5 years are considered to be at low risk of recurrence, smokers of $<20$ cigarettes a day at moderate risk and those of $>20$ at high risk.

Once we have seen the factors that we have to monitor to determine the risk of the patient, the next step is to fit the patient into one of the 3 categories and, based on which, we have to establish a regimen of maintenance visits with intervals older or younger. The diagram was evaluated in a 4-year longitudinal study and it was found that the established visit regime based on the assigned risk achieved a stability of the periodontal insertion of $100 \%$, except for patients positive for the IL-1 polymorphism, in which stability occurred in $90 \%$ of the cases (39). In Figure 2 We can see an example of a patient who has a moderate risk of disease recurrence. Below we observe the risk categories that we have to determine from the diagram:

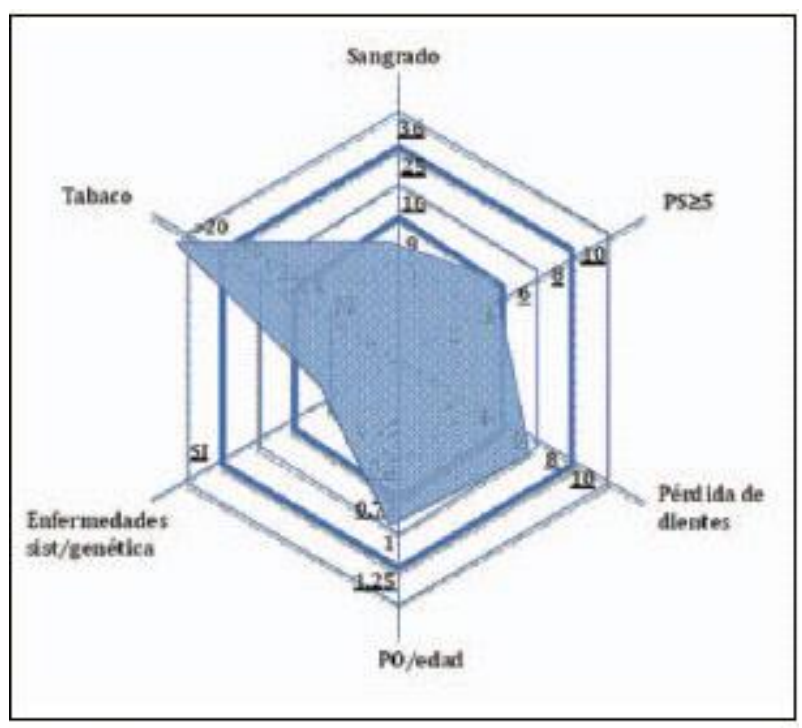

Fig. 2: Ejemplo de un diagrama funcional de un paciente que presenta riesgo moderado. 
- Low risk: It has all 6 parameters within the low risk zone, or at most, one in the moderate risk zone.

- Moderate risk: It has at least 2 parameters in the moderate risk category and at most one in the high risk category.

- High risk: It has at least 2 parameters in the high risk category.

b) Tooth risk

The risk of the tooth is determined by evaluating the parameters that we will discuss below, and it can be useful to determine the prognosis and function of the tooth on an individual level, as well as the treatment needs during the maintenance phase. We will take into account the following parameters:

- Position in the arch: It seems clear that dental crowding increases the risk of plaque accumulation and thus the appearance of gingivitis. However, this association with periodontitis remains to be demonstrated (40).

- Furcal involvement: It has been shown in both prospective (41) and retrospective $(13,42)$ studies that teeth with furcal involvement respond worse to treatment and are those that are lost before, so we must take this into account. condition in our maintenance plan.

- latrogenic factors: Poorly adapted crown margins and overflowing restorations are factors that promote plaque accumulation. Depending on whether the restorations are supragingival or subgingival, we must consider the risk posed by that tooth.

- Residual insertion: Teeth with advanced insertion losses can be functionally maintained individually or as prosthetic abutments for long periods of time (20), although they must be revised in order that an occlusal trauma can produce spontaneous exfoliation. of the tooth.

- Mobility: It is essential to distinguish between physiological mobility, as a consequence of loss of tooth support, and pathological mobility, as a consequence of excessive occlusal force. Both forms can be combined and bacterial plaque can be added as a factor, which could make the situation worse.

\section{c) Location risk}

Site risk analysis can be helpful in determining the presence of active periodontal disease and assessing the state of health or inflammation of the tissues. Furthermore, it is essential to determine the locations to be instrumented during maintenance therapy. Location risk analysis includes:

- Bleeding on probing: This parameter is the main one when monitoring patients in daily practice. Its main value lies in its high negative predictive value (28), which indicates that the absence of bleeding, using probing forces of no more than 25 grams, is a reliable indicator of periodontal stability. The predictive value of the test is more questionable, however, it seems that repeated positive results over successive maintenance visits increase the risk of future attachment loss, especially when combined with an increase in probing depth (27).

- Probing depth and insertion loss: Locations with increased probing depth and greater insertion loss are associated with subsequent insertion loss. 
- Suppuration: The sites that suppurate can be indicators that the disease has exacerbated to this level and that they require treatment.

\section{Action protocol}

Once we have analyzed the risk of the patient, the tooth and the location, the next step is to consider the different aspects that we have to take into account during maintenance therapy to act on the individual needs of each patient. Maintenance appointments will last approximately 1 hour and we will distribute them as follows:

?? Exam, reevaluation and diagnosis (10-15 $\mathrm{min}$.): We have to carry out a complete periodontal and dental exam, including implants and noting any changes that have occurred in the general medical history or in the patient's medication. All risk factors for the patient, the tooth and the location must be assessed in order to have the information so that at the end of the appointment the time of the next maintenance appointment is established. X-rays will occasionally be necessary, especially in endodontic teeth, prosthetic abutments and implants, in order to assess changes in bone levels, fractures or failures in endodontics and plaque retentive factors. This entire phase must be carried out in a regulated and systematic way.

?? Motivation, re-instruction and instrumentation (30-40 $\mathrm{min})$ : Once we have diagnosed the periodontal health status of the patient, the next step is to emphasize the importance of plaque control by the patient. If the patient has not been able to carry out a correct control of his plaque, we must give reinstructions on hygiene and motivation, always trying to look for positive reinforcement. We must then treat those areas that show signs of inflammation or increased pocket depths, focusing on eliminating the subgingival plaque and not the contaminated cement. Healthy areas should not be scraped a second time because it has been shown that they will thereby experience additional attachment loss (43).

?? Treatment of reinfected sites: In sites that present suppuration or that are difficult to access, such as furci, we must perform additional treatment to control the infection. Sometimes we will have to resort to local or systemic antimicrobials and even surgery. Regardless of the treatment we perform, our goal must be the complete elimination of the infection in order to avoid progressive insertion loss.

?? Polishing, fluoridations and next appointment planning: Finally, we will perform a polishing of all teeth to remove remaining soft deposits and stains and fluoridations, especially in patients with gingival recessions. Finally, we will establish when the next appointment will be based on the different risk indicators analyzed.

\section{CONCLUSÃO}

Maintenance treatment is an essential pillar in the prevention of periodontal diseases.

Regardless of the treatment modality we carry out, the treatment results return to the initial values, and even worsen, when the patient is not subjected to periodic periodontal maintenance by the professional (specialist).

Determining individual patient and site risk is critical to determining maintenance appointment intervals and locations that require additional treatment. 


\section{THE AUTHORS DECLARE NO CONFLICTS OF INTEREST.}

\section{REFERÊNCIAS}

1. Axelsson $P$, Lindhe J. The significance of maintenance care in the treatment of periodontal disease. Journal of clinical periodontology 1981 Aug; 8 (4): 281-94.

2. Lindhe J, Nyman S. The effect of plaque control and surgical pocket elimination on the establishment and maintenance of periodontal health. A longitudinal study of periodontal therapy in cases of advanced disease. Journal of clinical periodontology 1975 Apr; 2 (2): 67-79.

3. Rosling B, Nyman S, Lindhe J, Jern B. The healing potential of the periodontal tissues following different techniques of periodontal surgery in plaque-free dentitions. A 2-year clinical study. Journal of clinical periodontology 1976 Nov; 3 (4): 233-50.

4. Lindhe J, Westfelt E, Nyman S, Socransky SS, Haffajee AD. Long-term effect of surgical / non-surgical treatment of periodontal disease. Journal of clinical periodontology 1984 Aug; 11 (7): 448-58.

5. Lang NP, Tonetti MS. Periodontal risk assessment for patients in supportive periodontal therapy (SPT). Oral Health and Preventive Dentistry 2003; 1: 7-16.

6. Loe $H$, Theilade $E$, Jepsen SB. Experimental gingivitis in man. Journal of periodontology 1965; 36: 177-87.

7. Lindhe J, Hamp SE, Loe H. Plaque induced periodontal disease in beagle dogs. A 4-year clinical, roentgenographical and histometric study. Journal of periodontal Research. 1975; 10: 243-53.

8. Morrison EC, Lang NP, Loe H, Ramfjord SP. Effects of repeated scaling and root planning and / or controlled oral hygiene on the periodontal attachment level and pocket depth in beagle dogs. Journal of periodontal Research 1979; 14: 428-37.

9. Wesfelt E, Nyman S, Socransky SS, Lindhe J. Significance of frequency of professional tooth cleaning for healing following periodontal surgery. Journal of clinical periodontology 1983; 10: 148-56.

10. Loe $H$, Anerud A, Boysen $H$, Morrison E. Natural history of periodontal disease in man. Rapid, moderate and no loss of attachment in Sri Lankan laborers 14 to 46 years of 
age. Journal of clinical periodontology 1986 May; 13 (5): 431-45.

11. Becker W, Berg L, Becker BE. Untreated periodontal disease: a longitudinal study. Journal of periodontology. 1979 May; 50 (5): 234-44

12. Melo, Antônio Renato, Carlos Eduardo Vieira Gomes, and Fabio Alexandre Melo Campos. "Relação entre diabetes mellitus e o processo de osteointegração de implantes dentários." Brazilian Journal of Implantology and Health Sciences 1.5 (2019): 101-118.

13. Hirschfeld L, Wasserman B. A long-term survey of tooth loss in 600 treated periodontal patients. Journal of periodontology 1978 May; 49 (5): 225-37

14. Wilson TG, Glover ME, Malik AK, Schoen JA, Dorsett D. Tooth loss in maintenance patients in a private periodontal practice. Journal of periodontology 1987; 58: 231-5.

15. Nyman S, Lindhe J, Rosling B. Periodontal surgery in plaque-infected dentitions. Journal of clinical periodontology 1977 Nov; 4 (4): 240-9.

16. Kerr NW. Treatment of chronic periodontitis $45 \%$ failure rate. British Dental Journal. 1981; 150: 222-4.

17. Becker W, Becker BE, Berg LE. Periodontal treatment without maintenance. A retrospective study in 44 patients. Journal of periodontology 1984 Sep; 55 (9): 505-9.

18. Bragger $U$, Hakanson D, Lang NP. Progression of periodontal disease in patients with mild to moderate periodontal disease. Journal of Clinical Periodontology 1992; 19: 659-66.

19. Axelsson $P$, Nystrom B, Lindhe J. The long term effect of plaque control program on tooth mortality, caries and periodontal disease in adults. Results after 30 years of maintenance. Journal of clinical periodontology 2004; 31: 749-57.

20. Nyman S, Lindhe J. A longitudinal study of combined periodontal and prosthetic treatment of patients with advanced periodontal disease. Journal of periodontology 1979 Apr; 50 (4): 163-9.

21. Hamp SE, Nyman S, Lindhe J. Periodontal treatment of multirooted teeth. Results after 5 years. Journal of clinical periodontology 1975 Aug; 2 (3): 126-35.

22. Ross IF, Thompson RH, Jr. A long term study of root retention in the treatment of maxillary molars with furcation involvement. Journal of periodontology 1978 May; 49 (5): 238-44.

23. Carnevale G, Pontoriero R, di Febo G. Long-term effects of root-resective therapy in furcation-involved molars. A 10-year longitudinal study. Journal of clinical periodontology 1998 Mar; 25 (3): 209-14.

24. Murphy KG, Gunsolley JC. Guided Tissue regeneration for the treatment of periodontal intrabony and furcation defects. A systematic Review. Annals of periodontology 2003; 


\section{6: 266-302.}

25. Claffey N. Decision making in periodontal therapy. The re-evaluation. Journal of Clinical Periodontology 1991; 18: 384-9.

26. Joss A, Adler R, Lang NP. Bleeding on probing. A parameter for monitoring periodontal conditions in clinical practice. Journal of Clinical Periodontology 1994; 21: 402-8.

27. Claffey, Nylund, Kiger, Garrett \& Egelberg. Diagnostic predictability of scores of plaque, bleeding, suppuration and probing depth for probing attachment loss. Journal Clinical Periodontology 1990; 17: 108-14.

28. Lang NP, Adler R, Joss A, Nyman S. Absence of bleeding on probing. An indicator of periodontal stability. Journal of Clinical Periodontology 1990; 17: 714-21.

29. Calistro, Lucas Cesar, et al. "Peri-implantite e mucosite peri-implantar. Fatores de risco, diagnóstico e tratamento." Brazilian Journal of Implantology and Health Sciences 2.3 (2020): 64-83.

30. Knowles JW, Burgett FG, Nissle RR, Shick RA, Morrison EC, Ramfjord SP. Results of periodontal treatment related to pocket depth and attachment level. Eight years. Journal of Periodontology 1979; 50: 225-33.

31. Witter DJ, De Haan AFJ, Kayser AF, van Rossum GM. A 6-year follow-up study of oral function in shortened dental arches. Journal of Oral Rehabilitation 1994; 21: 113-25.

32. van der Velden U. The onset age of periodontal destructiojjn. Journal of Clinical Periodontology 1991; 18: 380-83.

33. Sanz-Sánchez I, Bascones-Martínez A. Diabetes mellitus: Its implication in oral and periodontal pathology. Av Odontoestomatol 2009; 25 (5): 249-63.

34. Calistro, Lucas Cesar, et al. "Peri-implantite e mucosite peri-implantar. Fatores de risco, diagnóstico e tratamento." Brazilian Journal of Implantology and Health Sciences 2.3 (2020): 64-83.

35. Ismail AL, Burt BA, Eklund SA. Epidemiologic patterns of smoking and periodontal disease in the United States. Journal of the Alabama Dental Association 1983; 106: 617-21.

36. Paraguassu, Éber Coelho, et al. "Implant installation in patients with periodontal disease history." Research, Society and Development 9.2 (2020): e39922009-e39922009.

37. Tomar SL, Asma S. Smoking-attributable periodontitis in the United States: findings from NHANES III. National Health and Nutrition Examination Survey. Journal of Periodontology 2000; 71: 743-51.

38. Labriola A, Needleman I, Moler DR. Systematic review of the effect of smoking on nonsurgical periodontal therapy. Periodontology 2000. 2005; 37: 124-37. 
39. Persson GR, Matuliene G, Ramseier CA, Persson RE, Tonetto MS, Lang NP. Influence of interleukin-1 gene polymorphism on the outcome os supportive periodontal therapy explored by a multi-factorial periodontal risk assessment model. Oral Health and Preventive Dentistry 2003; 1: 17-27.

40. Paraguassu, Éber Coelho. "O manejo da doença periodontal e peri-implantar." Brazilian Journal of Implantology and Health Sciences 2.8 (2020): 26-36.

41. Ramfjord SP, Caffesse RG, Morrison EC, Hill RW, Kerry GJ, Appleberry EA, Nissle RR, Stults DL. 4 modalities of periodontal treatment compared over 5 years. Journal of Clinical Periodontology 1987; 14: 445-52.

42. Clares, Mario Dormani, and Sarmento George Scilio. "Tratamento clínico da periimplantite com manutenção do tecido de granulação." Brazilian Journal of Implantology and Health Sciences 1.7 (2019): 192-206.

43. Lindhe J, Nyman S, Karring T. Scaling and root planning in shallow pockets. Journal of clinical periodontology 1982; 9: 415-8.

44. Gaunt F, Devine M, Pennington M, Vernazza C, Gwynneth E, Steen N, Heasman P. The cost-effectiveness of supportive periodontal care for patients with chronic periodontitis. Journal of Clinical Periodontology 2008; 53 (suppl 8): 67-82. 